\title{
História e literatura através do cinema
}

Maria Ignês Carlos Magno

Doutora em Ciências da Comunicação pela ECA/USP.

Professora do curso de Pedagogia do Centro Universitário Salesiano

de São Paulo e da Universidade Anhembi Morumbi.

E-mail: unsig@globo.com

As disciplinas história e literatura vivem na sala de aula uma grande contradição. Importantes em suas essências, dificilmente chegam aos olhos e aos corações dos alunos da forma como queremos, ou deveriam. Enxergar a história, saber-se parte dela e de uma sensibilidade, não é tarefa simples. Os acontecimentos são complexos, confusos; as palavras dos livros são difíceis; as histórias, pouco interessantes. Séculos separam os cotidianos. Numa época em que o hedonismo é a palavra de ordem e não o conceito filosófico, fica difícil explicar a necessidade do saber histórico e, mais ainda, a atualidade e a beleza dos clássicos da literatura universal e brasileira.

Pensando nas distâncias que separam os cotidianos e as produções culturais, e lembrando de como Camões foi recuperado por Renato Russo, cantado e entendido em sua essência por todos os jovens e não-jovens através da música, por que não buscarmos na linguagem cinematográfica, capaz de traduzir em imagens muitas histórias e linguagens, a inspiração para amenizar ou transformar as contradições e os confrontos em diálogos?

Diante disso, pensei em sugerir para este número da revista os filmes: Como era gostoso o meu francês e Memórias do cárcere, de Nelson Pereira dos Santos, e Anchieta José do Brasil, de Paulo Cezar Saraceni. Tendo a literatura como referência, os três filmes recuperam importantes períodos da história e da literatura brasileiras. Vale ressaltar que os filmes indicados são próprios apenas para os alunos do ensino médio, já que apresentam cenas de nudismo e tratam de questões sobre homossexualismo. É interessante que o professor assista ao filme antes de projetá-lo aos alunos.

\section{FICHA TÉCNICA}

Como era gostoso o meu francês

Direção - Nelson Pereira dos Santos

Roteiro - Nelson Pereira dos Santos

Argumento - Nelson Pereira dos Santos e Humberto Mauro (diálogos em tupi)

Direção de fotografia - Dib Luft

Montagem - Carlos Alberto Camuyrano 


\author{
Música - Zé Rodrix \\ Ano - 1971 \\ Duração - $91 \mathrm{~min}$ \\ L.C.
}

O filme conta a história de um aventureiro francês que torna-se prisioneiro dos índios tamoios, mas tem a execução adiada graças aos seus conhecimentos de artilharia. Embora precisem dele para lhes ensinar a manejar o canhão com o qual pretendem derrotar uma tribo rival, os índios marcam o dia de sua morte.

Durante o tempo que lhe resta, o francês aprende os hábitos dos tamoios e se une a uma jovem índia. A proximidade da morte não lhe agrada e ele procura, em vão, escapar. Depois da grande batalha entre tamoios e a tribo inimiga, o chefe Cunhambebe confirma a data da execução. O ritual antropofágico fará parte das comemorações pela vitória.

O filme é fruto de quatro anos de estudos, que envolveram a adaptação do livro Duas viagens ao Brasil ${ }^{1}$, de Hans Staden, e muita pesquisa antropológica. É falado em tupi-guarani, graças à assistência de Humberto Mauro ${ }^{2}$, um dos mais importantes cineastas brasileiros.

O filme de Nelson Pereira dos Santos pode ser trabalhado nas áreas de História e Literatura, porque amplia a possibilidade de leitura e conhecimento dessas duas disciplinas, bem como as suas inter-relações, além de favorecer a percepção da história por meio das leituras: poética e cinematográfica.

$\mathrm{Na}$ área de Português, o professor pode iniciar o estudo do filme com as leituras do poema I-Juca Pirama ${ }^{3}$, de Gonçalves Dias, e do segundo capítulo de Ubirajara: o guerreiro ${ }^{4}$. Na leitura de I-Juca Pirama, pode-se ressaltar um dos aspectos lúdicos da guerra - o canto, o ritmo, a cadência, a música; destacar a harmonia existente entre o elemento natural e a natureza, como se houvesse uma identidade entre índio/natureza. Pode-se também perceber os símbolos do nativismo e do nacionalismo, selecionar, tanto em Ubirajara como em I-Juca Pirama, os adjetivos caracterizadores e registrar passagens da figura feminina. $\mathrm{O}$ filme favorece a pesquisa e o estudo de Antonio Gonçalves Dias e dos clássicos brasileiros que, longe de serem apenas pedagógicos e parte das leituras obrigatórias, precisam ser entendidos como integrantes da literatura clássica brasileira.

$\mathrm{Na}$ área de História, o professor, após a projeção do filme, pode explicar o significado de guerra entre os tupis, discutir a relação entre a história, o cinema e a literatura, analisando as seqüências do filme em que a história e a literatura se inter-relacionam. Pode ainda apresentar os significados históricos dos nomes indígenas para melhor compreensão de sua cultura, e sugerir a discussão sobre as diferenças entre canibalismo e antropofagia.

Anchieta José do Brasil

Direção - Paulo Cezar Saraceni

Argumento - Marcos Konder Reis 


\author{
Fotografia - Marco Bottino \\ Música - Sergio G. Saraceni \\ Ano - 1978 \\ Duração - 140min
}

De acordo com a sinopse do filme, durante o período da colonização, a Companhia de Jesus exerceu importante papel na formação cristã do povo brasileiro. Seu maior expoente foi José de Anchieta, um padre jesuíta que integrou o relacionamento entre colonos europeus, povos indígenas e escravos negros. Através de um belíssimo poema épico, o diretor Paulo Cezar Saraceni relata com extrema sensibilidade o nascimento, vida e morte de José de Anchieta. Os fatos históricos, os elementos místicos e religiosos, assim como os mitos e as lendas são reunidos de uma maneira extraordinária, servindo como verdadeira chave para a interpretação da alma brasileira. Acompanha-se a luta de Anchieta em favor das comunidades indígenas brasileiras e vê-se o seu esforço sem fronteiras para compreender cada vez mais a verdadeira essência dessa raça que ele adivinhava estar condenada à extinção.

Em um trabalho conjunto entre literatura e história, alguns aspectos que podem ser analisados e discutidos com os alunos são: a postura dos representantes da Coroa portuguesa ao desembarcar no Brasil, os padres da Companhia de Jesus, José de Anchieta. Outro aspecto interessante é a relevância dos Autos para a compreensão da história que estava sendo construída sobre o Brasil, enfocando a visão dos colonizadores, da Coroa, dos índios, da Companhia de Jesus e das mulheres portuguesas. Ainda na direção dos diálogos, acompanhar os diálogos entre Padre Anchieta e Manuel da Nóbrega, entre os protestantes (luteranos e calvinistas) e os católicos, ressaltando o reflexo e o significado da reforma e a contra-reforma religiosa. Importante, para finalizar a reflexão, é a discussão sobre o significado do Brasil para os diversos personagens de sua colonização: o índio, os colonizadores portugueses, a Coroa, a Companhia de Jesus e o Padre José de Anchieta.

\section{Memórias do cárcere}

Direção - Nelson Pereira dos Santos

Roteiro - Nelson Pereira dos Santos

Fotografia - José Medeiros e Antonio Luiz Soares

Montagem - Carlos Alberto Camuyruano

Som - Jorge Saldanha

Ano - 1984

Duração - 124min

L.C.

O filme conta a história vivida por Graciliano Ramos $^{5}$ após ser preso em Alagoas, suspeito de colaborar com a Aliança Nacional Libertadora - ANL. Graciliano Ramos, que em 1936 ocupava o cargo de diretor da Instrução Pública, é conduzido ao Rio de Janeiro, onde sofre humilhação na Prisão da Ilha Grande. Da sua vivência, escreve, quinze anos depois, Memórias do cárcere.
5. RAMOS, Graciliano Memórias do cárcere. 34. ed. Rio de Janeiro: Record, 1998. 
Em 1936, o Brasil estava prestes a viver a ditadura que se instalaria em 1937, o chamado Estado Novo. Para compreender melhor o período e a história é preciso retomar os acontecimentos de 1935, quando os comunistas, agrupados em torno da Aliança Nacional Libertadora - ANL, iniciaram um levante militar no Rio Grande do Norte, com desdobramentos em Pernambuco e Rio de Janeiro. Sob a liderança de Luís Carlos Prestes, a Intentona Comunista pretendia depor Getúlio Vargas e implantar o regime comunista no Brasil. A rebelião fracassou e a repressão foi violenta. Mais de 6 mil pessoas foram presas. A simples suspeita de que uma pessoa era contrária ao governo bastava para levá-la à prisão. Graciliano Ramos foi uma delas. Preso em Alagoas, vagou de presídio em presídio sem nunca sequer ter sido ouvido; e Luís Carlos Prestes ficou dez anos numa solitária, submetido a tratamento tão desumano que o advogado Sobral Pinto chegou a invocar a lei de proteção aos animais em favor de seu cliente ${ }^{6}$.

Memórias do cárcere, de Graciliano Ramos, é um filme precioso para estudarmos e discutirmos a Era Vargas, o período entreguerras, a ascensão dos regimes nazifascistas e a fascização do mundo, a relação entre o Estado Novo e os regimes totalitários, a ambigüidade do governo Vargas, a censura, as prisões de intelectuais, artistas, escritores, jornalistas, a produção cultural e a cultura do silêncio que os regimes autoritários e ditatoriais impõem.

Se tomarmos o texto de Nelson Pereira dos Santos:

O cárcere em meu filme é uma metáfora da sociedade brasileira. No espaço exíguo da prisão a dinâmica de cada um é mais clara: a classe média militar, o jovem, a mulher, o negro, o nordestino, o sulista. O encontro com o prisioneiro comum, com o ladrão, o assaltante, o homossexual. Graciliano retratou tudo isso, lutando contra os próprios preconceitos e conseguiu nos deixar um testemunho generoso, aberto. Gostaria de transmitir, como era desejo de Graciliano, a sensação de liberdade. Sair da cadeia para sempre, para nunca mais voltar. A cadeia num sentido mais amplo, a cadeia das relações sociais e políticas que aprisionam o povo brasileiro.

6. ARRUDA, J. Jobson de; PILLETI, N. Toda a história. São Paulo: Ática, 2001.

7. SENA, João Cláudio de. Texto apresentado no ciclo de cinema do Colégio Nossa Senhora das Graças, durante as comemorações de 500 anos do Brasil, em abril de 1999.

8. BERNARDET, JeanClaude; RAMOS, Alcides

F. Cinema e história do Brasil. São Paulo: Contexto/Edusp, 1988.
As datas em que os filmes foram produzidos e a temática de cada um podem recuperar e desenvolver um estudo sobre a história e a produção cultural no Brasil na década de 1970, período do endurecimento da ditadura militar instaurada com o golpe de 1964.

Considerando ainda que história e literatura têm o cinema como veículo de suas narrativas, cabe estudar o próprio cinema como parte da produção cultural dos anos de 1970 e como forma de recuperar a literatura para poder dialogar com a história presente. Como era gostoso o meu francês (1971) busca na alegoria a possibilidade de falar da repressão militar, das relações entre brancos e índios, entre colonizadores e colonizados, dominadores e dominados, civilização e barbárie, desenvolvimento e subdesenvolvimento, articulados em torno da antropofagia ${ }^{7}$. Segundo Jean-Claude Bernardet ${ }^{8}$, "Anchieta José do Brasil é fruto de um período em que não se deixava mais à espontaneidade dos cineastas a produção dos filmes históricos [...]”. O filme histórico tornava-se cada vez 
mais assunto de estado, e Memórias do cárcere (1984) é uma dupla referência: ao mesmo tempo em que recupera e denuncia um passado ditatorial, remetenos à Campanha Diretas Já, e, como o próprio cineasta nos diz: "O filme é uma história de amor à liberdade".

Resumo: A autora propõe que as disciplinas de História e Literatura sejam narradas e entendidas através da linguagem cinematográfica, linguagem esta capaz de traduzir em imagens, em muitas histórias e códigos a inspiração para amenizar ou transformar as contradições e os confrontos em diálogos. Diante disso, ela sugere os filmes Como era gostoso o meu francês e Memórias do cárcere, de Nelson Pereira dos Santos, e Anchieta José do Brasil, de Paulo Cezar Saraceni. Tendo a literatura como referência, os três filmes recuperam importantes períodos da história e da literatura brasileiras.

Palavras-chave: cinema, história, literatura, linguagem cinematográfica.
Abstract: The author proposes the disciplines of History and Literature to be narrated and understood through cinematographic language, which is capable of translating into images, in many histories and codes the inspiration to soothe or to transform the contradictions and confrontations into dialogues. Taking that into account, the author also suggests the movies Como era gostoso o meu francês and Memórias do Cárcere, by Nelson Pereira dos Santos, and Anchieta José do Brasil, by Paulo Cezar Saraceni, as examples. Having Literature as reference, these three motion pictures presente important periods of Brazilian History and Literature.

Keywords: motion pictures, History, Literature, cinematographic language. 